\title{
VERBAL ANALYSIS AND ITS APPLICATION FOR THE ASSESSMENT AND MANAGEMENT OF THE INVESTMENT PROJECT RISK IN CONSTRUCTION
}

\author{
Galina Shevchenko ${ }^{1}$, Leonas Ustinovichius ${ }^{2}$ \\ ${ }^{1}$ Department of Economics and Management of Enterprises, Faculty of Business and Management, \\ Vilnius Gediminas Technical University, Sauletekio al. 11, LT-10223 Vilnius, Lithuania \\ ${ }^{2}$ Department of Construcrion Technology and Management, Faculty of Civil Engineering, \\ Vilnius Gediminas Technical University, Sauletekio al. 11, LT-10223 Vilnius, Lithuania \\ E-mails: ' galina.sevcenko@vgtu.lt (corresponding author); ${ }^{2}$ leonas.ustinovicius@vgtu.lt
}

\begin{abstract}
The paper investigates the investment decision-making, risk assessment and management problems faced by all participants of the investment process in construction. The main object of paper - risk of investment projects in construction. Companies often have to make investment decisions under uncertainty and therefore the study emphasizes the need, for carryng out investigations, developing metodology and intelectual decision making system that would holistically assess the whole available information to the investment project, increase the accuracy of risk assessment, improve project information management, reduce project risk factors for the occurrence of potential and would make informed investment decisions. The created and described verbal analysis method of the real alternatyve classification was integrated into the proposed model and implemented in practice.
\end{abstract}

Keywords: risk assessment, management, investment project, construction, verbal analysis, decisionmaking.

JEL Classification: G32; D81.

\section{Introduction}

Many scientists and practitioners analyze the company's investment objectives in a various aspects. Profitable activities of the company (productive investments) are possible only with the targeted investment decisions, weighed and managed risk, targeted and supervised investment and risk decisions.

Each and every company is affected by many risks due to the market economy conditions (Chorafas 2007). Besides the company's activities, there is high abundance of various risks as well. Business environment is constantly changing due to the stronger competition, international and internal dynamics of the market, demand and supply changes, systematic investment decisions need and many other factors. Recent research (Agrawal 2009; Merna, Al-Thani 2010; Ernst\&Young 2011; KPMG 2011) confirms that the risk assessment and management of relevance, addressing the company's investment objectives are understood and perceived by top management as an important enterprise performance management tool. However, managing link indicates that the existing risk assessment and management methodologies, guidelines and standards are often difficult or even impossible due to the specific adaptation problems, lack of professionals, information leakage risk, financial aspects and etc.

Companies' investment potential growth is directly related to the process attendant risks and to the assessments of many possible assumptions and results (Merna, Al-Thani 2010). Therefore, it is necessary to analyze a number of qualitative and quantitative criteria and to assess the occurrence of the risk and the potential profit-making opportunities in an investment decision making.

The quality management shortcomings, human factors, technology, contracts, environment, design errors and other factors are more often discussed then the financial causes analyzing companies' crises causes in the recent years (KPMG 2013). These problems often can not be measured by quantitative indicators, which in turn are eliminated from any risk calculations and analysis. The emerging problem (non-quantifiable indicators elimination from evaluation process) is usually analyzed after the event, but in most cases it causes considerable losses.

It is clear that risk assessment in making investment decisions is a multifaceted complex task that requires a separate detailed research in order to develop methods to facilitate correct/weigh/effective and rational investment decision making. 
Identification of the problems, the investment risk understanding, the effective and ensuring rational investment decision making highlights the need to find methods to achieve them.

Competition, inflation, changes in demand and supply as well as many other factors constantly alter the business environment (Chapman 2010; Apgar 2007). One can see that in the current markets (not taking into account financial institutions) risk assessment and management is still a relatively new and underdeveloped process. The above statement was made by analysing the causes of the bankruptcies and crises of Lithuanian and European companies, as well as the general reports of the state and other responsible institutions.

When analysing the causes of recent crises in companies, the financial causes are usually ignored (Ustinovichius et al. 2008a). Instead, the lack of quality management, as well as errors associated with personnel, technology, contract signing and planning, etc. can be observed more often. These problems (criteria) usually cannot be assessed quantitatively. Therefore, they are omitted from all calculations and further analysis. The considered problem (ignoring quantitatively unassessable criteria) has a very low chance of occurring and may be solved when the event has already happened. However, in most such cases, the company suffers very significant losses.

The problem of risk assessment and management has been analysed by the countries of the Western world for a very long time. Many risk identification, assessment and management models have been developed (Sadgrove 2009; Turskis 2008; Rutkauskas 2011). The main goal of these models is to predict, measure and decrease negative consequences of risks to company's performance. The analysis of these processes in Lithuania is a novelty. However, despite obvious benefits, usually, no investments are made in such analysis until a negative event takes place. Recent scientific papers are more often centred on research, describing qualitative evaluation of risk processes, emphasizing the importance of the fact that constantly changing market conditions can hardly be assessed by discrete values.

The importance of increasing the effectiveness of risk assessment and management in the Lithuanian construction sector is more apparent due to the reasons stated above.

Thus, the present paper analyses a decisionmaking copception based on qualitative estimates obtained by investigating risk assessment and management methods and applying these methods to assess investment project risks in construction companies.

\section{Analysis of modern approach to the investment project risk assessment and management}

\subsection{The investment project - subject of risk management}

An investment project may be described as a planned, goal-oriented creation and modernization of physical objects and technological processes, the preparation of technical and organizational documentation, as well as a set of managerial implementation methods. The investment project serves as a basis for the investment of capital into tangible assets (land, buildings, machinery and equipment) or intangible assets (services, consulting and other things needed to complete a project) with the goal to create, purchase or increase the value of the assets.

All projects are carried out according to the following project diagram (see Fig. 1), i.e. the plan is made, the problem is comprehended and, then, the means of putting the plan into effect are selected and, finally, all the goals are achieved.

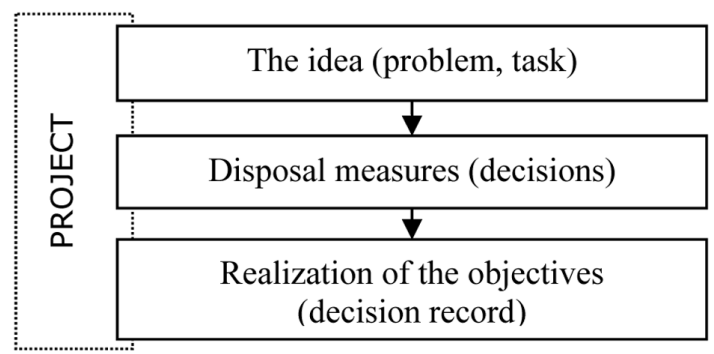

Fig. 1. General diagram of a project

(Source: Petravičius, Tamošiunienè 2008)

Realization of the objectives (decision record) The stages of the project as well as their components are usually standard, though it should be noted that it is important to ensure the balance between time and quality for every process at every stage (see Fig. 2).

In fact, the key features of the investment project are as follows (Shevchenko et al. 2008):

- it is assumed that the project should use the least possible amount of resources in order to maximize future profits;

- the project is planned, financed and implemented as a whole;

- the project may be the object of concrete financial agreements and have its own governing body; 


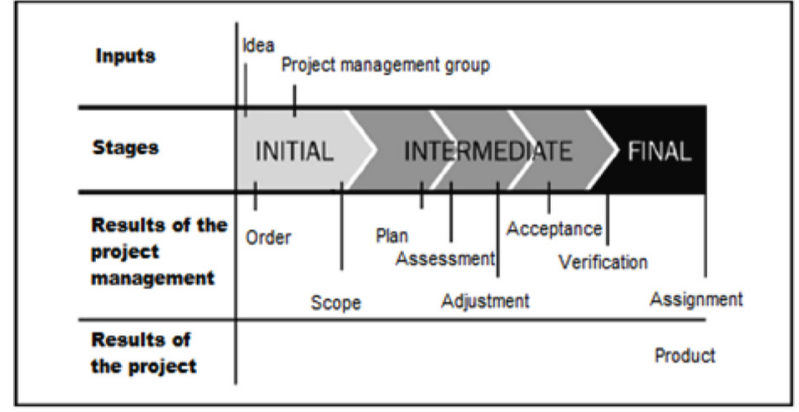

Fig. 2. Typical sequence of stages in the project life cycle (Source: Petravičius, Tamošiunienè 2008; Project Mangement Institute 2004)

- the project must have specific start and finish times, i.e. the period during which the planned goals are to be achieved (their achievement probability is comprehensively evaluated);

- the project has certain boundaries (geographical or even organizational).

All forms of capital investment are invariably associated with a certain risk (Hubbard 2009; Olson, Dash 2008). The specific features of investment activities are associated with the accumulation of all types of risk in a particular business area (Léautier 2010). Investment projects, including a set of technical, technological, organizational, financial, personnel and other decisions, made under uncertainty conditions, is a special area of investment activities. All projects are planned for the future and are likely to be altered to a larger or smaller extent, therefore, they are inevitably bound by uncertainty and risk. After all, one cannot know if the results of the project match the expected results, despite successful completion of particular project tasks. Every project task is affected by some sort of risk, which can cause the deviation from the planned course of execution.

\subsection{Risk assessment and management methods}

It is necessary to follow the scientific method in order to comprehensively review the risk analysis, evaluation methodologies and management structures and to propose improvement aspects and directions. The analysis of risk management literature revealed that there is no unified theory, the individual tests on a greater or lesser extent described in the risk analysis and assessment of the key steps are known (Maevskiy et al. 2013).

The risks, faced by companies, are important research subject for business and economic specialists that receive a lot of attention and various studies are performed in order to specify forms of risk, the sources of occurrence, estimation methods and measures for the prevention and neutralization (Rejda 2008).

The risk as by nature is a multifaceted concept, analyzed by various fields of science. There is also the lack of unified approach to the concept of risk, assigning actions to the risk factors and unanimously adopted risk classification in scientific literature. Probabilistic approach to the concept and the process result, widely encountered in risk management literature, often determines the choice of risk assessment methods. The qualitative component of the whole process usually remains eliminated from the risk assessment and management process as hard to express quantitatively. The paper analyzes the concept of risk in the construction investment activity context. Therefore, risk analysis and assessment methods analysis are mainly performed on the basis of management and economics specialist scientific publications, although the abundant input of the engineering is noticeable. 2 groups of the risk evaluation and assessment methods categorization can mostly be found in literature: qualitative and quantitative (Vaysblat et al. 2014; Haimes 2009; Khokhlov 2009; Norvaišienè 2006; Vilenskiy et al. 2002).

It should be noted that each group of methods have their own advantages and disadvantages but they are not interchangeable. Assessing the amount of information and available resources, the appropriate methods should be purposely used at different stages (Fig. 3). Their coordination is necessary at different risk analysis and assessment stages.

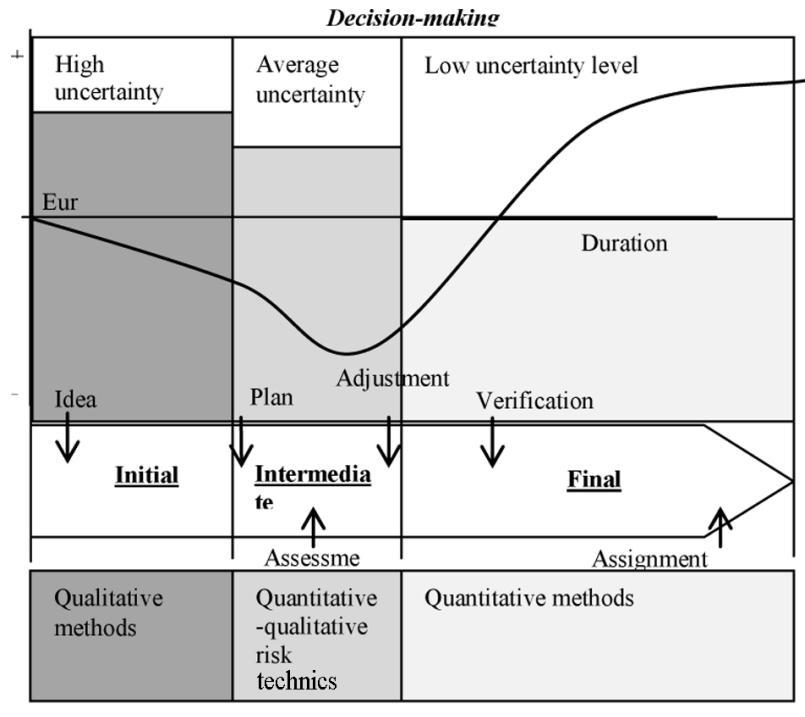

Risk analvsis, assesement and management techniques (methods)

Fig. 3. The typical investment project cash flow distribution and risk assessment and management techniques (methods) in the project life cycle (Source: compiled by the authors) 
In conclusion, it is noted, that the risk assessment and management models given in the literature, do not allow to fulfill the thorough construction investment solutions risk assessment and management. The most widely used (and literature considered to be reliable) methods often analyze only part of the available information (usually expressed in quantitative terms) do not include the quality-value rates in the risk assessment process. And of course, you can not create a reliable quantitative model and the more to interpret the results with unreliable variable assessment method, linking it with subsequent management processes.

Therefore measures, tools and techniques (methodology) that would help assess qualitatively and quantitatively expressed indicators, their impact on the final construction investment project risk level and also would help to make optimal investment decisions.

\section{Risk perception and assessment of the concept of creation}

Analyzing the investment project as a model for the company, it is analyzed as a subsystem of the economic system. There is also a model that describes the project output data dependency on the input parameters. External design parameters can be classified into macro and micro-economic and evaluated by different methods: statistical, economic-mathematical, expert, scenario methods, and so on.

Application of statistical methods in the investment project risk assessment is more difficult for lack of statistical data or their partial (uneven) existence, according the parameters which uniqueness is determined according to each investment project specifics. Also, these methods do not predict the parameter changes due to external factors changes, because the essential condition of the statistical data application is the stability of the external data.

Economic-mathematical and models do not ensure greater accuracy, comparing with the expert evaluations, but their application is significantly more expensive than the last methods. This explains the popularity of the expert evaluation and scenario methods for the investment designs, but the traditional mathematical approaches application in the context of these methods greatly reduce their performance and efficiency.

The efficiency of one or another mathematical approach for the investment project risks evaluation can be analyzed according to the following criteria:
- The application of the method should be based on the minimum number of the antecedent hypotheses that should be fundamental in a specific model and independent of the expert assessment;

- The method should allow to collect all the conscious and subconscious information from the expert;

- Expert's interview procedure should be as clear as possible and understandable to the interviewee.

- Mathematical substantiation of the method should allow accurate and rapid implementation of the calculations.

- Mathematical substantiation of the method should enable to assess the greatest possible number of feasibility scenarios.

Expert evaluation method is usually used on the basis of probability theory based on the system of the axioms, which is inadequate for a given task. This theory is characterized by the partial interpretation of the events' probable occurrence: it is not known what the specific experiment (project) result will be, but the percentage chance of one or another outcome is known at the invariably initial conditions for the multiple implementation of the same experiment. However, if the conditions are constantly changing and the experiment is implemented only once, this method has fundamental flows (Larichev, Moshkovich 1997). Therefore, such task, how to assess the occurrence of the event with a certain probability is, in fact, incorrect.

Another problem is that the random variables of the probability theory distribute according to certain laws (usually according the law of Haus). In this case the calculations are simplified considerably. This approach is ideal for the physical processes modeling, but is poorly supported by economic theory. The more, at the financial markets, where many transactions between the large number of market participants take place, random value distribution does not go according the Haus distribution.

So, if an expert is proposed to evaluate the standard tolerance and average of the random variable, it is incorrect for several aspects:

1. The entirely unjustified and in many cases incorrect assumptions are taken because of the nature of the random size distribution;

2. The task for the expert is to process a lot of information, compare/evaluate the influence/ impact of different parameters or to evaluate difficult parameters;

3. Some information that the experts have are more on a subconscious level and is completely ignored. 
These problems can be solved by verbal analysis (Fig. 4) that partially or completely helps to eliminate the above-mentioned mathematical approach problems.

The verbal approach for risk analysis schematically can be represented as follows:

1. Identification of the indicators (element/ factor) that will be included in the risk analysis;

2. Setting rules for the character processing (verbal (linguistic) collation of the variables with the quantitative variables);

3. Computer calculations and level (grade/ rank) settings;

4. Classes adjustment, combining the balance of the variables entirety;

5. The decision on the project/s.

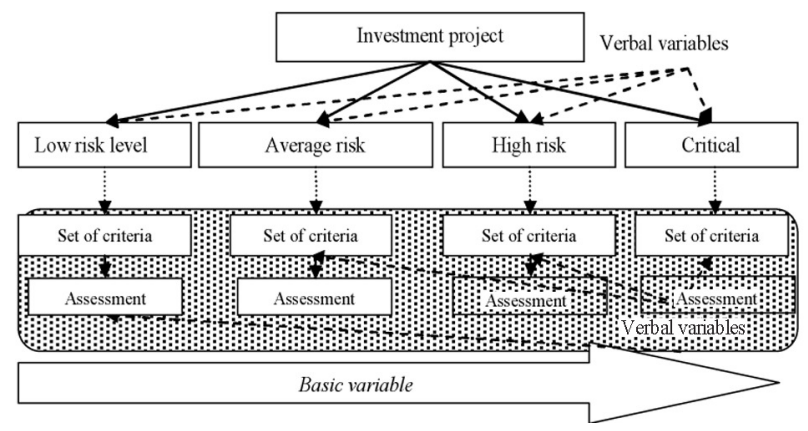

Fig. 4. Hierarchy structure of the verbal variables (Source: compiled by the authors)

Investment decision-making is focused on the choice of one solution among many others at certain conditions and certain factors or range of elements. The risk assessment in this case is very important, because the decision-maker must understand the reasons of the choice, which means - the level of assumed risk significance. Moreover, a person must understand how combined effect of the factors could affect the final decision and what factors can force the change of the result in the desired direction (Hopkin 2009).

In summary, it can be seen that the probability (mathematical) methods, as for the abovediscussed aspects, are often not in a position to assess the impact of the totality of the factors on the final design level of risk and on the result of the project - as a consequence. The numerical value, which is the result of mathematical probability method, requires a sufficiently detailed explanation of numerical values as well. Company frequently does not implement so many projects for their data to be used to carry out the distribution probability of one or another factor changes analyzing the values and numerical expressions of the factors. In addition, operating specifics of many companies show that, similar at first glance investment projects should be classified differently under more detailed analysis. Meanwhile, many factors (variables), such as: contractor's reliability, prestige of the company, employee training and others, do not have one approved (adopted) quantitative measure.

Thus, various formal risk assessment and management methods can not provide unambiguous recommendations in most cases. At the end it is always a person who is responsible for the decision made. That is why the expert assessment procedure is applicable at all stages of the risks assessment. It also should be noted that it is not appropriate to altogether refuse formal-economic (mathematical) methods, but the key issues such as:, is the profit big enough due to the level of risk; what is better faster but less or longer but more, can be solved by the decision-makers together with experts only. Therefore, the decision-making system in the organization should include expert-economic and formal procedures wherever possible.

The accounting and evaluation of the uncertainties task for investment projects risk assessment remains regardless of all the above mentioned aspects. Since probability methods of risk assessment is complicated, and many risk quantification is basically impossible, it makes perfect sense to try to analyze the risks in basic (or artificially introduced) language words (Ustinovichius et al. 2009, 2010). All this enables to apply the verbal decision analysis methodology for construction investment decision risk assessment and management problems solution.

\section{Verbal risk assessment model}

Risk management is a systematic process for integrating professional judgments about relevant risk factors, their relative significance and probable adverse conditions and/or events leading to identification of auditable activities (Migilinskas, Ustinovičius 2008). The world is created by a lot of decision-making methods that are used in various fields of human activity. Multi verbal decision analysis classifies real alternatives to authorize the Multipurpose options in different perspectives (Zavadskas et al. 2010; Shevchenko et al. 2013).

CLARA method (Classification of Real Alternatives) was created to deal with the classification task. This method can be carried out and the entire set of objects and a set of known classification experts minimizing the number of inquiries. The method can also be applied at a number of criteria loosely linear scale. 
These approaches consider options for prioritizing and significance directly and proportionally dependent on options to adequately characterize the system of indicators, the indicators values and weights sizes. Indicator values are determined, and the significance of the indicator values calculated by the experts. All this information can adjust the stakeholders (customer, users, etc.), according to their aims and opportunities. Therefore, the options reflect the results of the evaluation of experts and stakeholders in general the original data.

Investment project risk analysis based on using the financial and non - financial criteria helps to determine the present state and the prospects of enterprise performance (Shevchenko, Ustinovichius 2012). This is confirmed by close cooperation of the financing and mathematical modelling specialists and researchers. Usually, technological decisions which are made in financial analysis are based on optimization, prediction decision support systems, multicriteria analysis, artificial intelligence and stochastic models and methods.

From the perspective of performance (behaviour), one of the requirements to the results yielded by any of the available methods is the provision of explanations (Shevchenko et al. 2008). For example, a decision-maker (DM) should know why the alternative A seemed to be better than the alternative $\mathrm{B}$ and both of them are better than the alternative $C$. To satisfy this requirement, a decision making method should be transparent and capable of finding the correspondence between the data elicited from the DM and the final estimate of the alternatives. Only in this case, it is possible to get the explanations (Larichev 2002).

Practical application of verbal decisionmaking methods (VDM) is more advanced than the use of heuristic and axiomatic methods. Compared to a heuristic method, the verbal decision-making method has the advantage because the ways of getting information in this method are psychologically grounded, while all variations in data are mathematically explained. This analysis allows for evaluating the behaviour of the company's employees in decision-making, which is performed in steps, leading to the final decision. The verbal analysis methods are not perceived by a decision maker because he/she simply answers the questions asked by a computer in the language well understandable to him/her. Later, a decision maker checks if his/her preferences correspond to the recommended ones.

As mentioned above, most of the multicriteria methods require that the values of the criteria be defined quantitatively for determining the significances of various criteria. In using the methods of verbal analysis, the criterion values and weights (significances) are determined intuitively by a decision maker or expert and any additional calculations are not required.

A verbal analysis problem may be formally expressed as follows. Given:

1) $N$ is the number of the criteria evaluating the alternatives;

2) $n_{j}$ is the number of verbal estimates of the criteria;

3) $X_{j}=\left\{x_{j}^{1}, x_{j}^{2}, \ldots, x_{j}^{n_{j}}\right\}$ denotes estimates ranked in the order from the best to the worst on the $j$-th criterion scale;

4) a set of available vectors $Y=\left\{X_{1}{ }^{*}, X_{2}{ }^{*}, \ldots\right.$, $\left.X_{N}{ }^{*}\right\}$, consisting of estimates of the type $y_{1}=\left\{x_{1}^{k}\right.$, $\left.x_{2}^{m}, x_{N}^{t}\right\}$, with each vector $y_{i}$ having one of the scale values based on each criterion. The expression $y=\left\{X_{1}{ }^{*}, X_{2}{ }^{*}, \ldots, X_{N}{ }^{*}\right\}$ determines $N$-th system of evaluation whose each point is one of possible criterion estimates;

5) the alternatives determined from the set $A=\left\{a_{1}, a_{2}, \ldots, a_{n}\right\}$.

It is necessary to rank the alternatives according to the DM preferences.

Nowadays, computer software can assist many management techniques like sensitivity analysis and improve the efficiency of the analyzing process. Computer simulation packages are thought to be more realistic than theoretical calculations (Shevchenko et al. 2008). The method/ program CLARA can be successfully applied to classification of investment decisions/projects when the decision classes and the criteria used are thoroughly revised.

A method of comprehensive order classification. At the first stage, the alternatives of the set $Y$ are numbered in the specified order. In this case, it is valid that $y_{i}>y_{j} \Rightarrow \mathrm{i}<\mathrm{j}$. This preliminary numbering ensures that a particular alternative is considered when all the alternatives dominant over it had been already analysed.The use of the hypothesis of distinctness allows us to considerably reduce the number of questions to an expert, required to make the classification. Let us denote by $G^{i}$ a set of class numbers $Y_{l}(1 \leq 1 \leq M)$, admissible for the vector estimate $y_{i} \in Y$. Before questioning the DM (an expert), $G^{i}=\{1,2, \ldots, \mathrm{M}\}$ is assumed for $\forall y_{i} \in Y$, because we do not have any information about the expert's preferences. Finally, it is required that all $G^{i}$ consist of only one element. Suppose that the expert decided that the vector estimate $y_{i} \in Y$. should belong to the class 
$Y_{l}(1 \leq 1 \leq M)$, according to its global quality. Following the hypothesis of distinctness, in this case a vector estimate, described by a number of the criteria values, which are not less preferable for an expert, cannot belong to a less preferable class. Similarly, a vector estimate, described by a number of the criteria values which are not more preferable that those of $y_{i}$, cannot belong to a more preferable class. Consequently, the data, relating only to one vector estimate of $Y$, which were elicited from an expert, can result in the reduction of the sets $G i$, corresponding to other vector estimates. In this way, in a particular case, vector estimates can be referred to a particular class of vector estimates without being submitted to an expert. It is necessary to take into consideration the possibility of referring a particular vector to a particular class. The indicator $p_{i l}$ (assessing the possibility of referring the vector yi to the class $Y_{l}$ ) shows the proximity of the vector considered to the members of this class because the vectors of the same class usually make compact groups in multidimensional space. To calculate pil, the normalized distance between the vector yi and the center of the class $\mathrm{Ck}$ can be used. Relying on two indicators, $p_{i l}$ and $G^{i}$, a unified quantitative estimate of the informativity of any not estimated state $\Phi$ can be obtained:

$$
\Phi_{i}=f\left(\left\{p_{i l}, g_{i l} \mid l \in G^{i}\right\}\right),
$$

where $f$ is a certain real function, $g_{i l}$ is the number of vectors from $Y$ whose membership of a particular class becomes known (i.e. cardinal number of the respective set of the class numbers $G^{i}$ is equal to one) if the expert refers the vector $y_{i}$ to the class $Y_{l}$.

A subset of the alternatives $Y_{g}$ for which the set $G^{i}$ of the admissible classes contains more than one element is determined. If $Y_{g}$ is empty, pass on to stage 7 .

1. The indicators $p_{i l}$ are calculated for all the alternatives from $Y_{g}$ and $g_{i l}$ is determined for $\forall l \in G^{i}$.

2. The indicators $p_{i l}$ are found from the formula.

3. Based on the above indicators, the amount of information of the vector $y_{i}-\Phi_{i}$ is determined.

4. $y_{i} \in Y_{g}: \Phi_{i}=\max _{y_{j} \in Y_{g}} \Phi_{j}$ is determined.

5. The above vector is submitted to an expert to be referred to one of the classes.

6. The sets $G^{i}$ are modified in a accordance with the class specified to the vector by the expert.

7. The procedure is completed.
The detailed algorithm of CLARA method is presented in Ustinovichius et al. (2010).

\section{Method CLARA for investment risks evalua- tion and management}

Many researchers have pointed out that in construction it is essential to be able to take into account the impacts of cultural, social, moral, legislative, demographic, economic, environmental, governmental and technological change, as well as changes in the business world on international, national, regional and local real estate markets (Zavadskas et al. 2008; Ustinovicius et al. 2008b; Turskis 2008).

Every construction project is unique and each has different risk allocation, capital requirements, management teams, construction methods etc (Minasowicz 2008). All these factors could affect project cost, and thus it is necessary to identify and analyse the risks associated with project budget and realization. After a few iteration series expert (DM) can choose final decisions - Final class decisions (Fig. 5). Detailed description of these groups is provided in the first hierarchy level. Further the classification of the possible investment project risks must be established taking into consideration all levels of their multi-purpose quality descriptions - second hierarchy level. During that quality of the received results must be checked as well. Such risk evaluation work course is received following the drawn scheme - evaluations of the second hierarchy level criteria $\Rightarrow$ evaluations of the first hierarchy level criteria $\Rightarrow$ risk level.
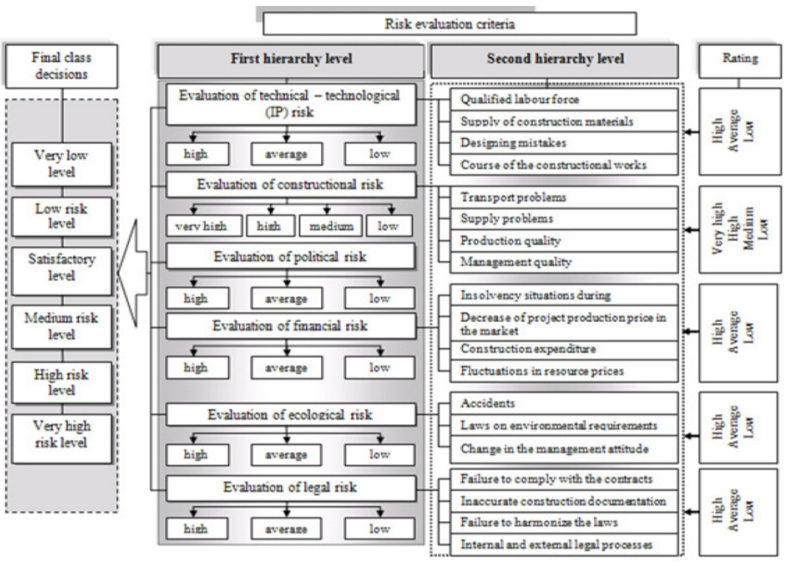

Fig. 5. The classificatory of investment risks level evaluation (Source: compiled by the authors)

Risk level might be established using the composed classificator, but a lot of criteria must be compared. It is a very difficult task for any person (for expert too), besides it takes a lot of time. 
Therefore, it is possible to use computer program CLARA (classification of real alternatives). This method (program) allows evaluating constructional investment project according to accurately established classes with the respectful offered criteria for risk size evaluation.

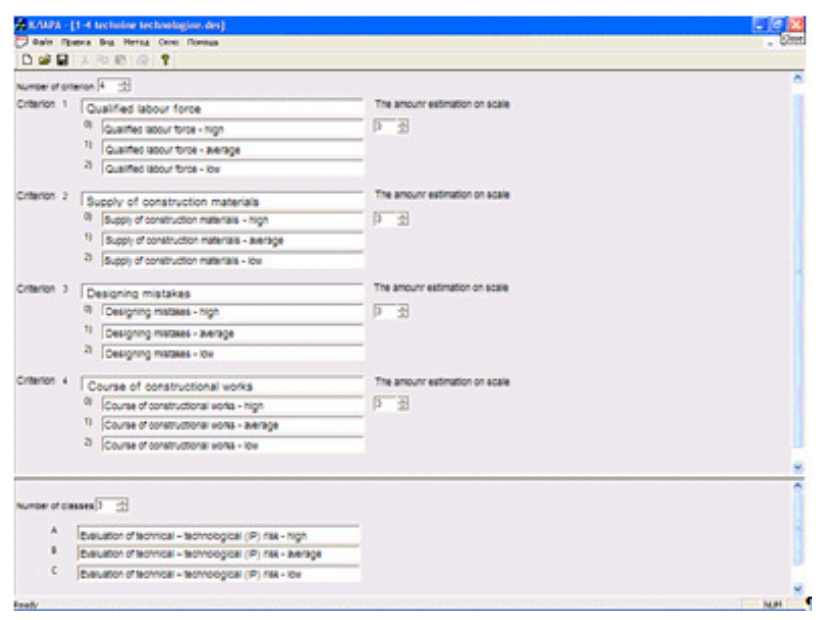

Fig. 6. Data input into the program

(Source: compiled by the authors)

Classificator establishment course. Data input into the program.

1 Stage - For second hierarchy level evaluation criteria are introduced (Fig. 6): Criterion $1-$ qualified labour force; Criterion 2 - supply of construction materials; Criterion 3 - designing mistakes; Criterion 4 - course of the constructional works.Criteria evaluation classes: Class A - high; Class B - average; Class C - low. Criteria 1-4 are chosen for evaluation of technical - technological risk. While analysing two projects (2 alternatives) the expert determines where the chosen labour force is qualified enough, where permanent continuous supply of materials will be ensured during the construction, what is the estimated course of works. After the project is analysed, it is determined if there are no mistakes in it. Other stages are input adequately to stage 1 .

Classification implementation in the program. After introducing all the criteria that will be taken into consideration while evaluation 3 investment alternatives, the last stage is performed, i. e. the criteria are compared. The comparison is made in the following way: the program selects one evaluation of each criterion and composes their combinations. The expert assigns the available evaluation combination to the respectful class.

When the assigning is finished, a transfer is made to the next stage (by pushing the button "NEXT"). Another evaluation combination is pro- vided. This is done up to a moment, until all the combinations are allotted to the respectful class.

During the work the expert might make a mistake or change his opinion, therefore, contradictions might appear in his answers.

In such case, the program shows a warning that contradictions have occurred and it will ask to confirm the new answer or to change it.

After the work is finished, the program saves all the data, perform analysis and shows the number of the given DM questions, the number of eliminated combinations. It also shows how many of evaluates combinations were allotted to classes $\mathrm{A}, \mathrm{B}$ or $\mathrm{C}$ (Fig. 7). Evaluating of all second hierarchy level criteria are established in an analogous way.

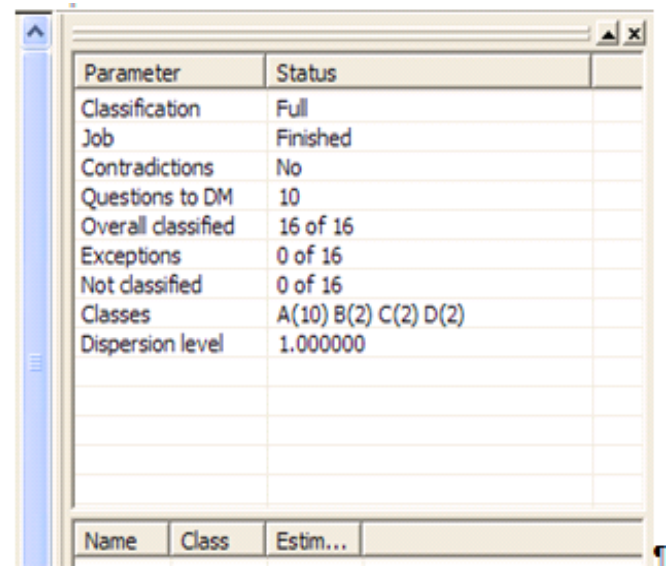

Fig. 7. The data of program

(Source: compiled by the authors)

Final solving analysis. The final analysis is performed according to the evaluations of the first hierarchy level. After the final analysis is performed, we get evaluation data, i.e. we establish risk levels (Fig. 8).

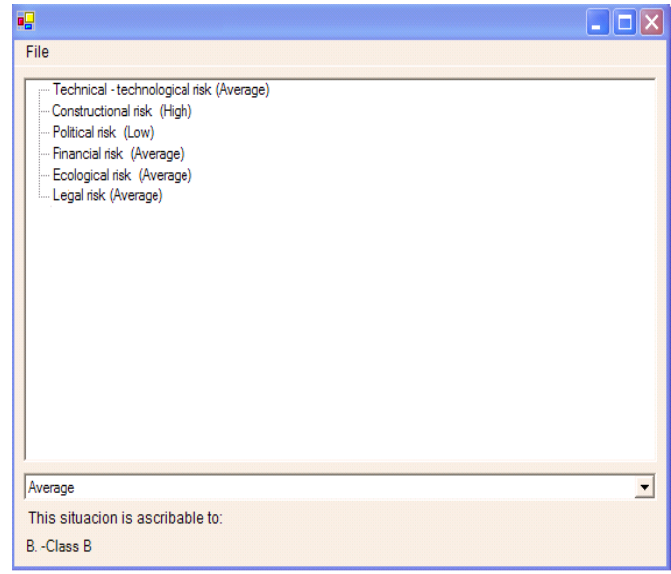

Fig. 8. Data base (I hierarchy level) (Source: compiled by the authors) 


\section{Conclusions}

The literature review of lithuanian and foreign scientitist researches in the field of risk analysis has been carried out. After the mentioned scientific literature analysis it can be concluded that a number of relevant factors of the investigated activity/project should be considered so that to assess the risk: social, economic, political, cultural, etc. New methods, which are capable of analysing the carried out activity or project risc fully (complex), should be created and applied.

The premise that risk assessment and management must be an integral part of the overall decisionmaking process necessitates following a systematic, holistic approach to dealing with risk. Such a holistic approach builds on the principles and philosophy upon which systems analysis are grounded.

Most researchers of decision-making methods recognize and emphasize the difference between the existing standard methods and human percetion and ability of information processing. The methods based on verbal analysis rely on scientific approaches, taking into account various disciplines and considering psychological criteria, which are particularly important.

Following the review of the literature, it leads to the conclusion that there is a lot of decisionmaking methods and techniques in the world. Many normative methods that been presented previously as a "universal" approach, i. e. optimal solution, but applying them to different areas to solve problems revealed deficiencies in the application of these methods: low reliability, complexity of use, low evaluation of the alternatives.

The possibilities of the theory of verbal analysis for the project and the contractor's risk assessment and management were analyzed. It was found that verbal analysis methods may be relevant challenges in the less structured decision-making areas. These include risk assessment problems. The global experience analysis indicated that the proposed risk assessment methods do not allow to carry out a comprehensive companies' investment decisions (projects) risk assessment and multi criteria (multipurpose) analysis that evaluate the indicators (criteria) described not only by discrete but also lexicographical values, therefore the paper proposes the verbal analysis method CLARA for the problems' solution.

The developed risk assessment verbal analysis method CLARA acting on the basis of multipurpose classification. The proposed the real alternatives classification algorithm (CLARA) helps to create and actualize complete and compatible data bases that allow creating more efficient construction investment decisions conditions.

\section{References}

Agrawal, R. C. 2009. Risk management. Jaipur, IND: Global Media.

Apgar, D. 2007. Rizikos intelektas [Risk intelligence]. Verslo žinios. 211 p. (in Lithuanian).

Chapman, R. J. 2010. Simple tools and technues for enterprise risk management. Chichester: John Wiley \& Sons, Ltd. 466 p.

Chorafas, D.N. 2007. Risk management in financial services. Elsevier Ltd. 340 p.

Ernst\&Young. 2011. Restart: European attractiveness survey.

Haimes, Y. Y. 2009. Risk modeling, assessment, and management. $3^{\text {rd }}$ ed. Hoboken, New Jersey: John Wiley \& Sons, Ltd. 1009 p.

Hopkin, P. 2009. Holistic risk management in practice. $2^{\text {nd }}$ ed. Withersbys Insuranse. Withersbys Seamandship International Ltd. $220 \mathrm{p}$.

Hubbard, W. D. 2009. The failure of risk managementwhy it's broken and how to fix it. Hoboken, New Jersey: John Wiley \& Sons, Inc.

Khokhlov, N. V. 2009. Upravlenie riskom. Moskva: Yuniti-dana. 239 p.

KPMG. 2011. International survey of corporate responsibility reporting 2011.

KPMG. 2013. International survey of corporate responsibility reporting 2013.

Larichev, O. I. 2002. Close imitation of expert knowledge: the problem and methods, International Journal of Information Technology and Decision Making 1(1): 27-42. http://dx.doi.org/10.1142/S021962200200004X

Larichev, O. I.; Moshkovich, E. M. 1997. Verbal decision analysis for unstructured problems. Boston: Kluwer Academic Publishers. $155 \mathrm{p}$. http://dx.doi.org/10.1007/978-1-4757-2638-1

Léautier, T.-O. 2010. Corporate risk manaement for value creation. $2^{\text {nd }}$ ed. Published by Risk Books, a Division of Incisive Financial Publishing Ltd. $242 \mathrm{p}$.

Maevskiy, F. V.; Vyatkin, V. N.; Gamza, V. A. 2013. Risk-menedzhment. Preventivnoe upravlenie. Izdatel'stvo Nauka i obrazovanie. 380 p.

Merna, T.; Al-Thani, F. F. 2010. Corporate risk management. 2nd ed. Chichester: John Wiley \& Sons, Ltd. $422 \mathrm{p}$.

Migilinskas, D.; Ustinovičius, L. 2008. Methodology of risk and uncertainty management in construction's technological and economical problems, in The $25^{\text {th }}$ International Symposium on Automation and Robotics in Construction (ISARC 2008): selected 
papers, 26-29 June 2008, Vilnius, Lithuania. Vilnius: Technika, 789-794.

Minasowicz, A. 2008. Analiza ryzyka $w$ projektovaniu przedsięwzięcia budowlanego [Risk analysis in the design of the building project]. Warsaw, Poland: Publishing house of the Warsaw university of technology. 161 p. (in Polish).

Olson, D. L.; Dash, W. D. 2008. Enterprise risk management. Financial engineering and risk management, Vol 1. World Scientific Publishing Co Pte. Ltd. 252 p.

Norvaišienè, R. 2006. Imonès investiciju valdymas [Companies investment management]. Kaunas: Technologija (in Lithuanian).

Petravičius, T.; Tamošiunienè, R. 2008. Using project risk management process in investment appraisal, in The First International Science Conference "Knowledge Society”. The II International Science Conference for Young Researchers "Technical Science and Industrial Management" Scientific Proceedings I, 3-5 September 2008, Sozopol, Bulgaria, 3: 39-46.

Project Mangement Institute. 2004. A guide to the project management body of knowledge. $3^{\text {rd }}$ ed. PMBOK Guides. 390 p.

Rejda, G. 2008. Principles of risk management and insurance. Publisher: Prencipe Hall.

Rutkauskas, A. V. 2011. On the susitanability of regional competitiveness development considering risk, Technological and Economic Development of Economy 14(1): 89-99.

http://dx.doi.org/10.3846/2029-0187.2008.14.89-99

Sadgrove, K. 2009. The complete guide to business risk management. $2^{\text {nd }}$ ed. GOWER. Bodmin, Cornwall: MPG Books Ltd. 330 p.

Shevchenko, G.; Ustinovichius, L. 2012. Tendencies and prospects of risk and uncertainty management of enterprise investment projects, in The $7^{\text {th }}$ International Scientific Conference "Business and Management'2012”, 10-11 May 2012, Vilnius, Lithuania, 208-216.

Shevchenko, G.; Ustinovichius, L.; Andruskevicius, A. 2008. Multi-attribute analysis of investment risk alternatives in construction, Technological and Economic Development of Economy 14(3): 428-443.

http://dx.doi.org/10.3846/1392-8619.2008.14.428-443

Shevchenko, G.; Ustinovichius, L.; Łoniewski, K. 2013. Risk assessment improvement in the investment project management: verbal analysis methods, Project Planning in Modern Organization: Studia Ekonomiczne 137: 83-103.
Turskis, Z. 2008. Multi-attribute contractors ranking method by applying ordering of feasible alternatives of solutions in terms of preferability technique, Technological and Economic Development of Economy 14(2): 224-239.

http://dx.doi.org/10.3846/1392-8619.2008.14.224-239

Ustinovichius, L.; Shevchenko, G.; Barvidas, A.; Ashikhmin, I. V.; Kochin, D. 2010. Feasibility of verbal analysis application to solving the problems of investment in construction. Automation in Construction: An International Research Journal 19(3): 375-384.

http://dx.doi.org/10.1016/j.autcon.2009.12.004

Ustinovichius, L.; Turskis, Z.; Shevchenko, G. 2008a. Multi-attribute analysis of investment risks in $\mathrm{Se}$ lected Papers of The 25 $5^{\text {th }}$ International Symposium on Automation and Robotics in Construction (ISARC 2008), 26-29 June 2008, Vilnius, Lithuania. Vilnius: Technika, 682-687.

Ustinovichius, L.; Barvidas, A.; Vishnevskaja, A; Ashikhmin, V. I. 2009. Multycriteria verbal analysis for the decision of construction problems, Technological and Economic Development of Economy 15(2): 326-340.

http://dx.doi.org/10.3846/1392-8619.2009.15.326-340

Ustinovicius, L.; Kochin, D.; Kutut, V.; Shevchenko, G. $2008 \mathrm{~b}$. Verbal analysis of renovation investment strategy of old town, in Selected Papers of The $25^{\text {th }}$ International Symposium on Automation and Robotics in Construction (ISARC 2008), 26-29 June 2008, Vilnius, Lithuania. Vilnius: Technika, 397410.

Vaysblat, B. I.; Malekova, L. A. 2014. Optimizatsiya upravleniya investitsionnoy deyatel'nost'yu predpriyatiya $v$ usloviyakh riska. N. Novgorod: Nizhegorodskiy filial MESI. $118 \mathrm{p}$.

Vilenskiy, P. L.; Livshits, V. N.; Smolyak, S. A. 2002. Otsenka effektivnosti investitsionnykh proektov: Teoriya i praktika. Moskva: Delo. 888 p.

Zavadskas, E. K.; Turskis, Z; Ustinovichius, L.; Shevchenko, G. 2010. Attributes weights determining peculiarities in multiple attribute decision making methods, Inzinerine ekonomika - Engineering economics 1(21): 32-43.

Zavadskas, E. K.; Ustinovichius, L.; Turskis, Z.; Shevchenko, G. 2008. Application of verbal methods to multi-attribute comparative analysis of investments risk alternatives in construction, Computer Modelling and New Technologies 12(4): 30-37. 